\title{
ICT기반의 물정보 통합관리시스템 개발 연구 The Development Study on the Integrated Management System for Water Information based on ICT
}

\author{
홍석민 $\cdot$ 장암* ${ }^{\dagger}$ \\ Sok-min Hong $\cdot$ Am Jang*, ${ }^{+}$ \\ 한국수자원공사 * *성균관대학교 건설환경시스템공학과 \\ K-water * *Department of Environmental Engineering, Sungkyunkwan University
}

(Received November 13, 2017; Revised December 12, 2017; Accepted December 27, 2017)

\begin{abstract}
As the development of ICT technology, in order to solve the problem of scattered water information's availability, WINS(Water management Information Networking System) by the Ministry of Land, Infrastructure and Transport was established and has been operated since 2004. However, there has been a disadvantage of providing specialized and limited information to the water resources sector mainly and a lack of active sharing of information because of no compulsory provision of information sharing between participants. In order to solve these problems, this paper carried out system development study, to do this, the status of domestic water information was surveyed and domestic and overseas related systems were compared and analyzed. The latest ICT technology was used to realize the contents as screen, and the user interface definition was created to present a role model of integrated water management through maximizing visualization by combining GIS and realtime data and providing space-time integrated information. These prior studies reached to actual construction of the ICT-based integrated management system for water information by K-water. This system is in service to the public installed in the water information portal, "MyWater". Key Words : Water Information, Big Data, Integrated Water Management, IWRM, SWG
\end{abstract}

요약 : ICT 기술의 발전으로 분산된 물정보의 활용성 문제를 해결하기 위해 '04년 국토부 주도의 물관리정보유통시스템 (WINS)이 구축, 운영 중에 있으나, 수자원 분야에 특화 및 일부 제한된 정보만 제공하는 점과 각 기관의 정보제공 강제성이 없어 적극적인 정보공유가 미흡하다는 단점이 있어 왔다. 본 논문은 이러한 문제들을 해결하기 위한 일환으로 ICT기반의 물 정보 통합관리 시스템 개발을 위한 국내 물정보 현황을 조사하고, 국내외 관련 시스템들을 비교, 분석하였다. 콘텐츠를 화면 으로 구현하기 위해 최신의 ICT기술과 GIS, 실시간 데이터를 결합하여 시각화를 극대화하고 시공간 통합정보 제공을 통해 통합물관리의 롤 모델을 제시할 수 있도록 화면정의서를 작성하였다. 연구결과 및 향후 기대효과는 다음과 같다. 첫째, 기 확보된 정부부처, 물기관의 물정보를 활용하여 전국의 수자원, 수도, 지하수 시설물의 위치와 실시간 운영정보를 한 눈에 볼 수 있도록 함으로써 정보기반의 통합물관리 모델을 제시한다. 둘째, 모든 공공기관의 수문 관측 정보와 생활, 농업, 공업용수 수용가 정보를 통합할 경우 이를 홍수, 가뭄 분석에 활용하여 예경보 정확도를 향상시킬 수 있고, 사후 복구 및 지원방향에 대한 의사결정에도 활용할 수 있을 것이다. 셋째, 댐 방류량, 각 수위국 수위 정보, 각 지자체 하천 취수장 및 정수처리시설 운영현황, 용수공급구역 정보 및 화학단지, 공업단지 등 점오염원 배출지역 정보를 통합하면 수원에 오염원 유입시 신속한 대응 및 의사결정이 가능해질 것이다. 이러한 선행연구를 바탕으로 K-water는 ICT기반의 물정보 통합관리 시스템을 개발하 였고, 이를 물정보포털인 “MyWater"에 탑재하여 일반 국민들에게 서비스 중에 있다.

주제어 : 물정보, 빅데이터, 통합물관리, IWRM, SWG

\section{1. 서 론}

\section{1. 연구 배경 및 필요성}

' 12 년 UN-Water 조사결과에 의하면 전세계 국가의 $68 \%$ 이상이 통합물관리를 도입 중이며, 모든 국가로 확산 중에 있다고 한다. 호주의 경우, 6 개 연방 및 주정부가 관련된 Murray Darling Basin Agreement를 통해 물정책 및 프로그 램을 통합 후, '08년부터 유역관리청 설치 및 연방정부 차 원의 통합물관리를 진행 중이라고 한다. ${ }^{1)}$

우리나라의 경우 최근 기후변화 패턴을 보면 ' 90 년 이후 2 3년마다 크고 작은 가뭄과 7년 주기의 극한가뭄이 발생 하고 있다고 한다. '09년 전국 77 개 시군 23 만 명 제한급수
이후 ' 15 년 발생한 42년만의 극심한 가뭄이 좋은 예일 것 이다. 또한 과거에 비해 호우일수는 감소하나 홍수피해를 유 발하는 강우강도는 더 커지는 방향으로 강우특성이 변화되 고 있는 것도 예의주시할 대목이다(시간당 $50 \mathrm{~mm}$ 이상 집중 호우 발생빈도 : 11회/년('79 '97년) $\longrightarrow$ 20회/년('98 '06년) 약 1.8 배 증가). 한편, 가뭄으로 인한 수량 문제뿐만 아니라 수질과 수생태 문제 또한 우리를 괴롭히고 있다. ' 14 년 7 8 월에는 37일간 팔당 취수장 및 상수원에 지오스민 발생, ' 16 년 4 5월에는 한강수계 상류에 시네드라 발생 등 정수처리 장애 및 물이용 제약 빈도는 날로 증가하고 있는 실정이다. 이에 따라 유역전체를 하나의 유기체로 통합관리함으로 써 효율성, 공평성, 지속가능성을 극대화시키자는 유역단위 
물관리의 필요성은 오래전부터 대두되어 왔으나 우리의 물 관리 여건은 현실을 반영하지 못하고 있다. 수량과 수질 관 리는 부처, 목적별로 분산 관리되고 있어 지역간의 물갈등 까지 부추기고 있는 상황이다. 수량측면에서는 댐건설, 취 수, 도수로 인한 물배분 우선순위와 수량 확보, 유역 변경, 요금 등의 비용부담 등이 주요 갈등요인이며, 수질측면에서 는 경북, 대구와 경남, 부산 갈등에서 보듯 맑은 물 확보를 위한 취수원 이전 요구로 지역간 갈등이 증폭되고 있다. 새 정부 출범시마다 물관리 일원화를 위한 논의도 있어 왔고 관련 법 제정 움직임도 있어 왔으나 매번 부처간 이견으로 무산되어 왔다(19대 국회에서는 의원입법으로 물관리기본 법 및 수자원조사법 제정을 추진하였으나, 19 대 국회 종료 에 따라 자동 폐기). 과거 수차례 시도에서 보듯, 기존 물관 리 조직 및 업무중심의 물리적 통합은 쉽지 않다. 따라서 본 연구에서는 효율성 및 실현 가능성을 고려한 물정보 중 심의 통합 ${ }^{2}$ 을 위한 방향 등을 제시하고자 한다.

\section{2. 연구 목표}

본 연구의 목표는 흩어져 있는 정보를 한데 모아 각계각 층의 눈높이에 맞는 맞춤형 물정보를 쉽고 빠르게 제공하 는 물정보 통합관리시스템 개발을 위한 개념설계에 있다. 이를 통해 물정보 통합관리시스템 개발의 발판을 마련함으 로써, 일반국민에게는 이해하기 쉽고 생활에 밀접한 정보 를, 전문가들에게는 실시간과 시계열 데이터 등의 원천 데 이터와 빅데이터 분석을 통한 고품질의 정보를 제공하고자 한다. 이러한 목적을 달성하기 위하여 다음의 목표수준을 부여하고 통합시스템 개발연구를 추진하였다.

(1) 기존의 유사 시스템들이 표 형태로 제공하던 실시간 데이터를 GIS기반의 시공간 연계 데이터로 제공한다.

(2) 물순환 과정을 고려한 통합적 관점에서 지리정보와 시계열의 특성을 파악할 수 있는 물정보를 제공한다.

(3) 사전조사를 통해 각계각층의 니즈에 부합하는 콘텐츠
를 제공한다.

(4) 일반국민, 전문가 등 수준이 서로 다른 사용자의 눈높 이에 맞는 콘텐츠를 제공한다.

(5) K-water 자체생산 및 외부연계 물정보를 대상으로 우 선 개발하되, 향후 물정보 확대를 염두에 두고 시스템 확장이 용이하게 개발한다.

(6) 끝으로, 제공되는 데이터의 품질을 일정수준 이상으 로 확보, 유지하기 위해 데이터 품질관리 인프라를 함께 개발한다.

\section{2. 관련 개발 및 연구동향}

\section{1. 정보통합 국내외 동향}

\subsection{1. 국토부 WINS(물관리정보유통시스템)}

통합시스템 개발 이전부터 구축, 운영 중인 국내 정보통 합의 대표적인 사례는 물관리정보유통시스템, WINS이다. WINS는 물관리 정보화 사업을 10 대 과제로 선정한 관계 부처 합동「물관리 종합대책」확정('96) 이후, 실무협의회, 기본전략 수립, 표준 마련 등을 거쳐 '04년부터 구축 운영 중에 있다. ${ }^{3)} 5$ 개 부처, 12 개 기관 등에서 개별 생산, 관리 중인 관측, 운영 데이터(수문, 기상, 댐, 하천, 지하수, 수질 등 66개 항목)를 국토부 주관 하에 유통시키고 있다. 각 참 여 부처, 기관별로 보유하고 있는 DB서버를 WINS 공유서 버와 XML 웹서비스 기술을 이용, 연계하여 필요한 데이터 를 다운로드 할 수 있도록 구성하였다(Fig. 1).

그러나 WINS는 기관간 공유표준 부재로 물정보 활용시 기관별 $\mathrm{DB}$ 구조 파악 및 변환이 필요하여 정보처리 효율성 이 떨어지며, 특히 공유기관이 증가할수록, 정보공유가 더 욱 복잡해지고 분석에 시간과 노력이 많이 소요되는 단점 이 있다. 더욱이 자료 제공의 강제성이 없고, 기관들의 적 극적인 정보공유가 미흡하여 서비스 활성화를 위한 제도적 장치 마련이 필요한 실정이다. 참여기관만 공유가 가능하

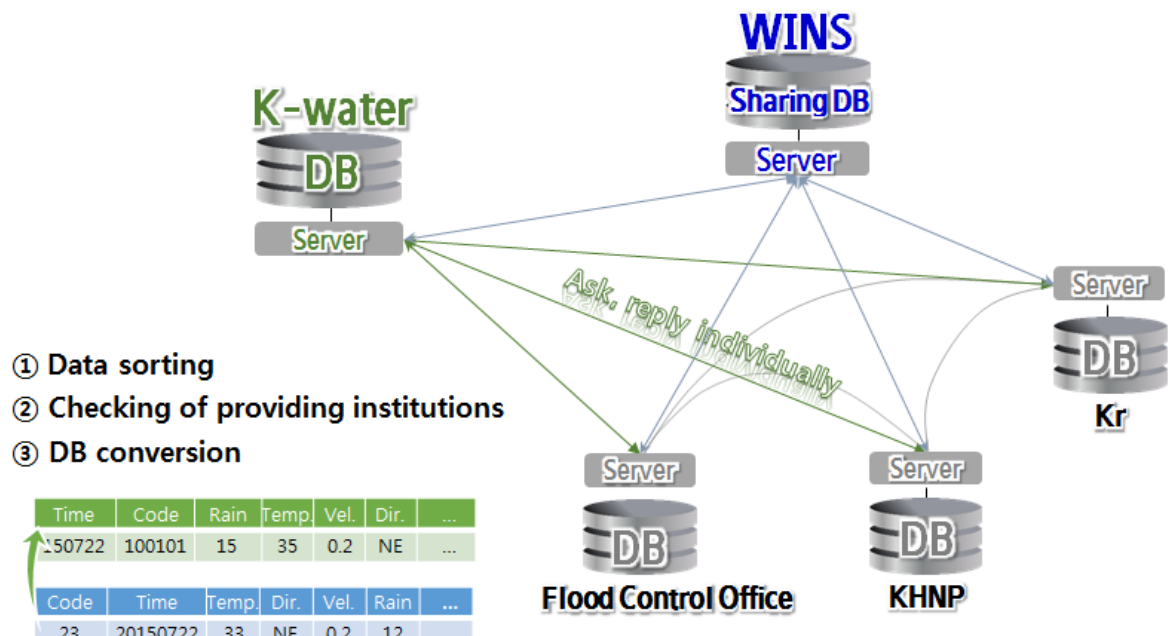

Fig. 1. WINS data sharing system 
다는 제약조건이 있고, 공유항목에 있어서도 지자체 및 환 경부 보유 상수도 정보가 미흡하다.

\subsection{2. 환경부 국가상수도정보시스템과 물환경정보시 스템}

환경부는 산재된 상수도 분야 주요 정보의 수집, 통합관 리를 통해 효과적인 상수도 정책 수립을 위한 기반을 마련 하고, 수집된 수질 및 시설자료 등 상수도 정보를 수요자 관점의 다양한 서비스로 제공하기 위하여 국가상수도정보 시스템 웹페이지를 구축 운영 중에 있다. ${ }^{4}$ 수질현황, 시설 정보 및 기술정보 등 상수도 관련 정보를 제공하고 있으며, 수질입력프로그램을 통합하여 전국 취정수장의 원수 및 정 수 수질검사결과를 제공 중이다. 또한 최신 상수도 통계와 지자체 수도정비기본계획 보고서를 파일형태로도 제공하 고 있다. 이와 별도로 환경부는 수질, 수생태, 오염원 등 수 계오염특성 정보의 종합적 관리와 정보서비스 향상을 위하 여 물환경정보시스템을 구축 운영 중에 있다. ${ }^{5)}$ 국립환경과 학원을 주관기관으로 하여 "GIS기반 물환경정보서비스", “실시간수질정보시스템" 등을 통한 다양한 수질, 수생태 정보를 제공해 오고 있다.

\subsection{3. 미국 CUAHSI의 수문정보시스템(HIS)}

CUAHSI는 Consortium of Universities for the Advancement of Hydrologic Science, Inc의 약어로 '수문학 분야의 발전 을 위한 대학 협의회’를 의미한다. 현재 CUAHSI는 미국 내 112 개의 가입 대학과 7 개의 준가입대학, 그리고 16 개 국제가입국가로 이루어져 있다. CUAHSI는 미국과학재단 (National Science Foundation), NSF의 지원을 받아 운영되 고 있으며, 물과 인간생활, 지구환경, 그리고 사회에 대한 핵 심적인 역할에 대한 이해를 높이고, 물 관련 과학을 발전시 키고 사회적인 복지를 증진시키기 위해 다양한 연구를 진 행함으로써 미국의 수문학관련 과학기술개발과 교육에 이 바지 해오고 있다. 이러한 CUAHSI의 연구활동 중 하나가 수문정보시스템(Hydrologic Information System, HIS)이다. CUAHSI는 물과 관련된 자료는 각종 정부기관, 학술단체, 비정부단체 등 여러 출처에서 비롯되며, 물과 환경시스템에 대한 이해는 이러한 많은 자료들(식생, 토양, 지질, 물이용 등) 간의 상호작용을 이해하는 것이 필수적이고, 물 관련 과 학을 발전시키기 위해서는 이러한 자료의 출처를 발굴하고, 통합하여 이를 분석하는 기술개발이 필요하다는 것을 인식 하고 HIS를 개발하기에 이르렀다.)

HIS는 CUAHSI에서 수행하는 연구활동의 하나로서 학문 적, 교육적 또는 실용적 목적을 위한 수리, 수문 자료와 응 용 프로그램, 자료의 표준화, 시뮬레이션 모델 등 통합적인 정보화시스템을 의미한다. 이러한 연구활동은 궁극적으로 고품질의 자료에 대한 접근성을 용이하게 하고 신뢰성 있 는 수문분석을 가능하게 하였다. HIS는 다음과 같은 세 개 의 핵심적인 요소로 구성되어 있으며, 이 요소들은 Fig. 2 와 같이 상호작용을 통해 구동되게 된다. 미국은 CUAHSI

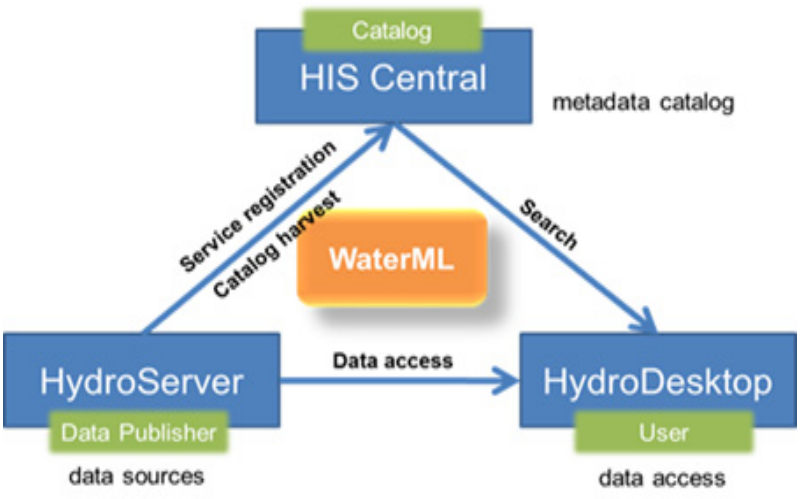

Fig. 2. Concept of HIS in CUAHSI.

$\mathrm{HIS}$ 를 통해 정보통합 및 유통체계를 확립하고, 지속적으로 데이터를 축적 중에 있다.

\subsection{K-water의 정보통합 움직임}

K-water는 최초 주전산기 도입('78) 이래 Homepage 개설 ('96), OASIS 재구축('05), 댐수도 통합정보시스템 구축('03), 수자원통합정보시스템 개선('13), 통합 수질예측대응시스 템 구축('14) 등 경영, 기술분야의 정보화를 지속 추진해 오고 있다. 국가 물정보 포털 WAMIS('98), 국가 물관리정 보유통시스템('03) 등 국가 수자원 정보화 구축을 지원하고 지자체 홍수재해 통합관리사업(실시간 수문관측시스템+홍 수재해 모니터링)을 추진함으로써 지자체의 재난대응체계 기반을 제공해 왔다. 또한 종합물관리 정보시스템(K-HIT) 및 표준 수운영시스템(iWater) 개발 등을 통해 통합 물관리 기술 개발 및 Package화로 동분야의 기술성장을 주도해 오 고 있다. 과거 박근혜 정부 시절, 국정운영의 방향을 정부 3.0 으로 정하고 개방, 공유, 소통, 협력의 가치를 강조함에 따라, 물과 관련하여 국민과 최접점에 위치한 K-water의 고 민이 시작되었다. 이에 ' 14 년 미래발전 8대과제 중 하나로 ‘물정보통합’을 선정하고, 분야별, 기관별로 분산된 물정보 를 개방, 공유하여 기후변화 대응력을 높이고 국가, 국민에 게 유용한 정보를 제공하기로 하였다. '14. 7월 특별전담반 구성 및 운영계획 $\mathrm{CEO}$ 보고 이후, 수자원, 수도, 지하수 정보 등 광범위한 물정보를 통합, 융합하여 물정보 이용의 가치를 높이고, 보다 나은 시설물 운영관리 및 대국민 서비 스를 확대하고자 ' 15 년 물정보기술원을 설립하고 ICT기반 미래 물관리 선도 및 Global 물시장 개척을 위한 핵심기술 육성에 힘쓰기에 이른다.

\section{3. 물정보 통합관리시스템 설계}

\section{1. 개발 프로세스}

\subsection{1. 기본방향}

통합시스템 설계의 기본방향은 개발자 시각의 물정보를 고객 맞춤형의 물정보 콘텐츠로 재구성하고, 활용 편의성 제 


\begin{tabular}{|l|}
\hline \multicolumn{1}{|c|}{ As Is } \\
\hline Developer viewpoint \\
Needs lack \\
Internal system mainly \\
Limitation
\end{tabular}

\begin{tabular}{|l|}
\multicolumn{1}{c|}{ To Be } \\
\hline $\begin{array}{l}\text { Customer first } \\
\text { Customized contents } \\
\text { Various type } \\
\text { Open data }\end{array}$ \\
\hline
\end{tabular}

Fig. 3. Development concept of the integrated system.

\begin{tabular}{|c|c|}
\hline $\begin{array}{l}\text { Business system Information } \\
\text { system Needs analysis }\end{array}$ & Frequently \\
\hline & $\begin{array}{l}\text { - Business system survey \& analysis } \\
\text { - Domestic and overseas system analysis } \\
\text { - Analysis of the needs of the general public, government, business } \\
\text { world, academia, and institute }\end{array}$ \\
\hline Extract and create content(draft) & Frequently \\
\hline & - Writing a definition(content of service and plan of execution) \\
\hline \multirow[t]{2}{*}{ Content Design } & When determining content promotion \\
\hline & $\begin{array}{l}\text { - Create detailed work performance plan } \\
\text { - (Big Data) The difficult task is to connect academics and researchers } \\
\text { - (Consultation) If expert opinion is required } \\
\text { - (Information security) When establishing and expanding information } \\
\text { network }\end{array}$ \\
\hline Content performance verification & Before service beginning \\
\hline
\end{tabular}

Fig. 4. Integrated system development procedure.

고 및 물정책 의사결정 도구로써의 기반을 마련하는 것이다 (Fig. 3). 통합시스템에 표출되는 물정보는 우선, K-water가 기 확보하고 있는 물정보를 활용한다. 향후 국내외 파트너 십을 통하여 물정보 통합을 지속 확대하고, 데이터 표준화
와 품질관리를 통한 고품질의 통합 물정보를 생산, 관리 및 제공해 나갈 것이다. 국내뿐 아니라 해외로의 물정보 공유, 확산을 위하여 글로벌 수준의 데이터베이스 표준모델 및 전송표준도 향후 개발할 필요가 있다. 또한, 수자원, 수도,

Table 1. System functional requirements for integrated system (some excerpts)

\begin{tabular}{cc}
\hline Requirement & \multicolumn{1}{c}{ Integrated system planning and development direction } \\
\hline \hline Definition & Basic development direction for integrated system construction \\
\hline - Production of contents to make it accessible and fun for everyone \\
- Developing so that the manager can easily manage it considering performance and convenience \\
- Using more consistent implementation technique for future integration and expansion \\
- It is designed and developed considering the development of the latest technology \\
- Maintaining consistency of graphics through establishment and design of style guides for consistent design, and documentation of \\
- letter size, spacing, graphics processing standards for text \\
- If the linked data is external site, be sure to provide a new window, but do not allow users to open many windows at once \\
- Do not make duplicate content with the same content, and if multiple configurations are inevitable, support multiple content \\
- Providing contents using the server of existing external web service \\
- Tools, programs, and materials used for development should be free from legal problems such as infringement of intellectual \\
property rights and should be upgradable in the future. \\
\hline Requirement \\
\hline \hline Mefinition screen design configuration \\
\hline Main screen and menu configuration for easy accessibility from user viewpoint and function to provide various water information \\
\hline - Main and sub-design reflected the latest trend design \\
- Menu and screen design intuitive and easy to use \\
- Screen construction with real time data in mind \\
- Sharing information such as data status and statistical data, etc. \\
- Providing linked services through SNS, blog, external homepage and various methods(API, etc.) \\
\hline
\end{tabular}


지하수의 물정보를 통합하고 GIS기반의 시공간 연계 물정 보를 제공하는 것으로 개발 concept을 수립하였다. 즉, 물순 환 과정을 고려한 통합적 관점에서 지리정보와 시계열의 특성을 파악할 수 있는 물정보를 제공하자는 것이다. 통합시 스템 개발은 Fig. 4의 절차에 따라 수행한다.

\subsection{2. 기능요구사항(SFR, System Function Requirement)}

목표 시스템이 반드시 수행하여야 하거나 목표 시스템을 이용하여 사용자가 반드시 할 수 있어야 하는 기능(동작) 은 Table 1과 같이 정의하였다. ${ }^{7)}$

\section{2. 화면정의서 작성}

\subsection{1. 작성 원칙}

통합시스템 개발의 사전단계에 있어서 화면정의서의 명 확한 작성은 누차 강조해도 지나침이 없다. 화면정의서란 콘 텐츠 메뉴 항목에 대하여 최종적으로 사용자에게 서비스되 는 미래의 화면(User Interface)을 머릿속으로 구상하고 구 상한 내용을 사전에 그려보는 것을 의미한다.

대개 정보의 표출형태는 지도, 그래프(막대, 선 그래프 등 의 종류까지도 구상), 표, 그림, 글 등이 있으므로 해당 콘 텐츠에 알맞은 표출형태 및 배치를 구상하여 작성하는 것 이 중요하다. 그리는 방법은 여러 가지가 있을 수 있으나 다음의 네 가지 정도가 가능하다.

(1) 기존 시스템(K-water, WAMIS, USGS 등 국내외 유사 시스템)에서 필요한 부분을 화면캡처해서 ppt 등으로 구성하여 양식에 입력

(2) 구글, 네이버 등에서 찾은 그림이나 ppt의 클립아트 등을 이용하여 보는 사람이 이해할 수 있는 정도의 수준으로 작성하여 입력
(3) 인터넷 등에서 찾기가 어렵다면, 직접 종이에 그림으 로 그려서 스캔이나 사진을 찍어 양식을 작성

(4) 그림 그리기가 정말 힘들다면(머릿속에 생각은 있는 데 정말 그리기 힘든 그림이거나, 콘텐츠를 말로 설 명할 수는 있는데 그림으로는 생각이 안날 경우) 그 림을 제외하고 글로 이해하기 쉽도록 상세히 기술

화면정의서는 가능한 상세하게 작성하는 것이 원칙이다. 콘텐츠의 화면구성, 그에 해당하는 데이터항목을 확인하는 것이 주목적중 하나이므로 화면 안에 여러 콘텐츠가 혼재 되어 있을 경우에는 콘텐츠에 따라 화면을 분할하고 번호 를 기입하고 데이터 항목에 그 번호를 표시했다. 화면정의 서 작성시 고려한 사항은 다음과 같다.

(1) 최근의 디자인 경향은 많은 내용을 두루마리 종이에 넣듯이 하나의 화면에 넣고 아래로 스크롤하여 보는 경향이 있는 반면, 화면정의서는 세로 칸이 작은 한 페이지로 되어 있으므로 작성시에는 실제 구현될 화 면을 여러 화면정의서로 분할하여 작성하여도 무방하 며, 이 경우 화면에 번호를 붙여서 작성

(2) 데이터 항목이 엑셀 항목에 없을 경우에는 다른 기관 소유여부 등 데이터를 어디에서 구할 수 있는지 담당 자가 최대한 조사 필요. 또한 이럴 경우, 소스위치부 터 테이블명에 대한 자세한 설명기술 요망

(3) 화면정의서는 꼭 한 페이지로 작성할 필요는 없으므 로 내용이 많다면 내용안에 “별도설명”으로 적고 별 도의 페이지를 할애하여 작성

\subsubsection{User Interface 정의}

통합시스템은 K-water가 기 보유중인 국내 수자원, 상하수

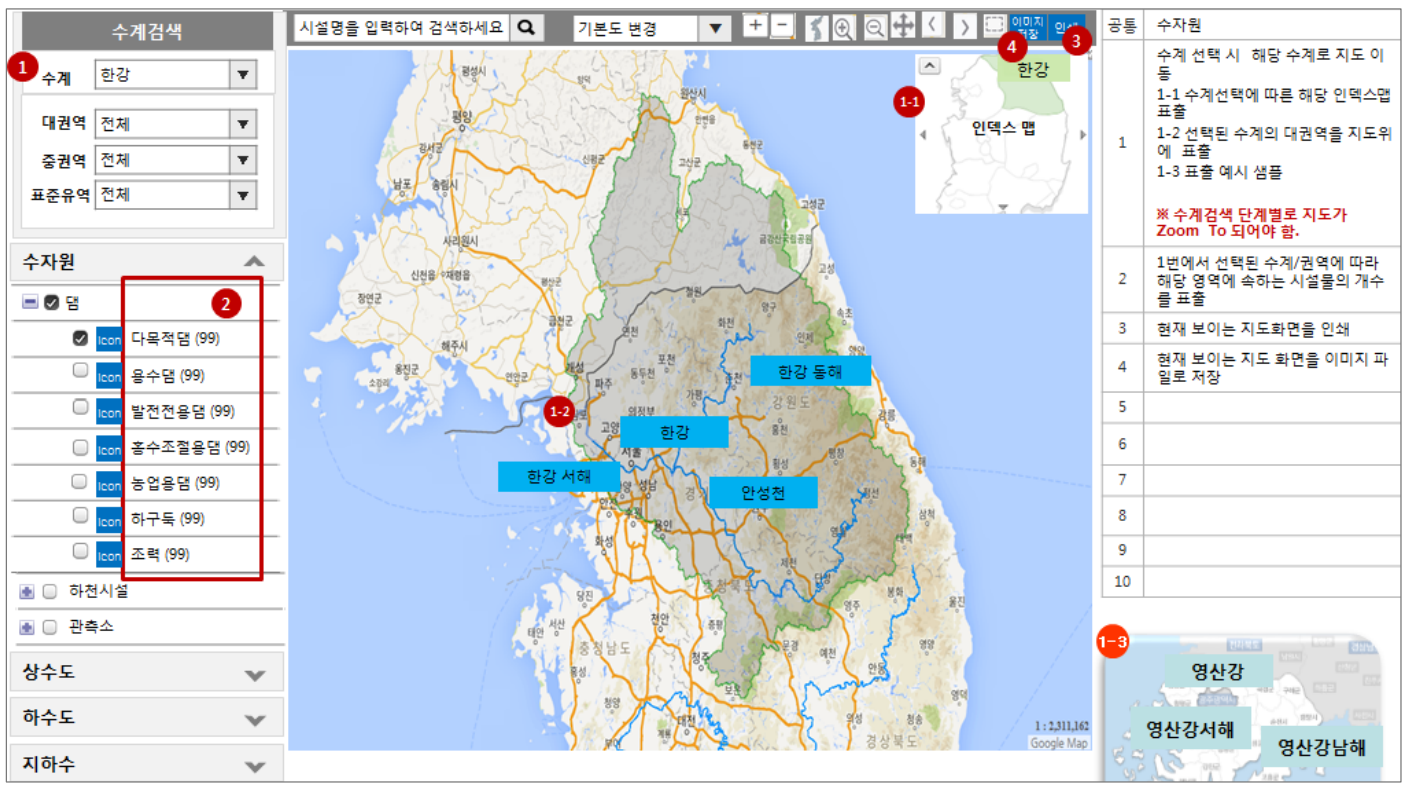

Fig. 5. User interface definition (water resources). 
도, 지하수의 물정보를 GIS기반으로 콘텐츠화하여 서비스 하는 것이다. 이에 따라 메뉴 구성은 수자원, 상수도, 하수 도, 지하수로 나누어 구성하였으며, 수자원의 경우 수계별 로, 수도의 경우 행정구역 단위로 검색이 가능하도록 구성 하였다(Fig. 5, Fig. 6)

수자원은 수계 선택시 해당 수계로 지도가 이동되며 수 계선택에 따른 해당 인덱스맵 표출 기능을 넣었다. 선택된 수계의 대권역을 지도위에 표출하고 수계검색 단계별로 지 도가 확대되도록 하였다. 선택된 수계 권역에 따라 해당영
역에 속하는 시설물의 개수를 표출하고 현재 보이는 지도화 면을 인쇄 또는 이미지 파일로 저장할 수 있도록 정의하였다 (Fig. 7). 수도는 메인메뉴에서 해당사업(광역, 지방 등) 클릭 시 해당사업 레이어 디폴트 값이 표출되도록 정의하였다.

즉, 광역상수도로 들어가면 광역상수도 레이어, 지방상수 도로 들어가면 지방상수도 레이어가 표출되도록 하였다. 사 업장 레이어는 기본적으로 정수장을 선택하도록 하였다(Fig. 6). 행정구역 선택시 해당지역으로 지도가 이동하고, 구역 선택에 따른 해당 인덱스맵을 표출토록 하였다. 선택된 행

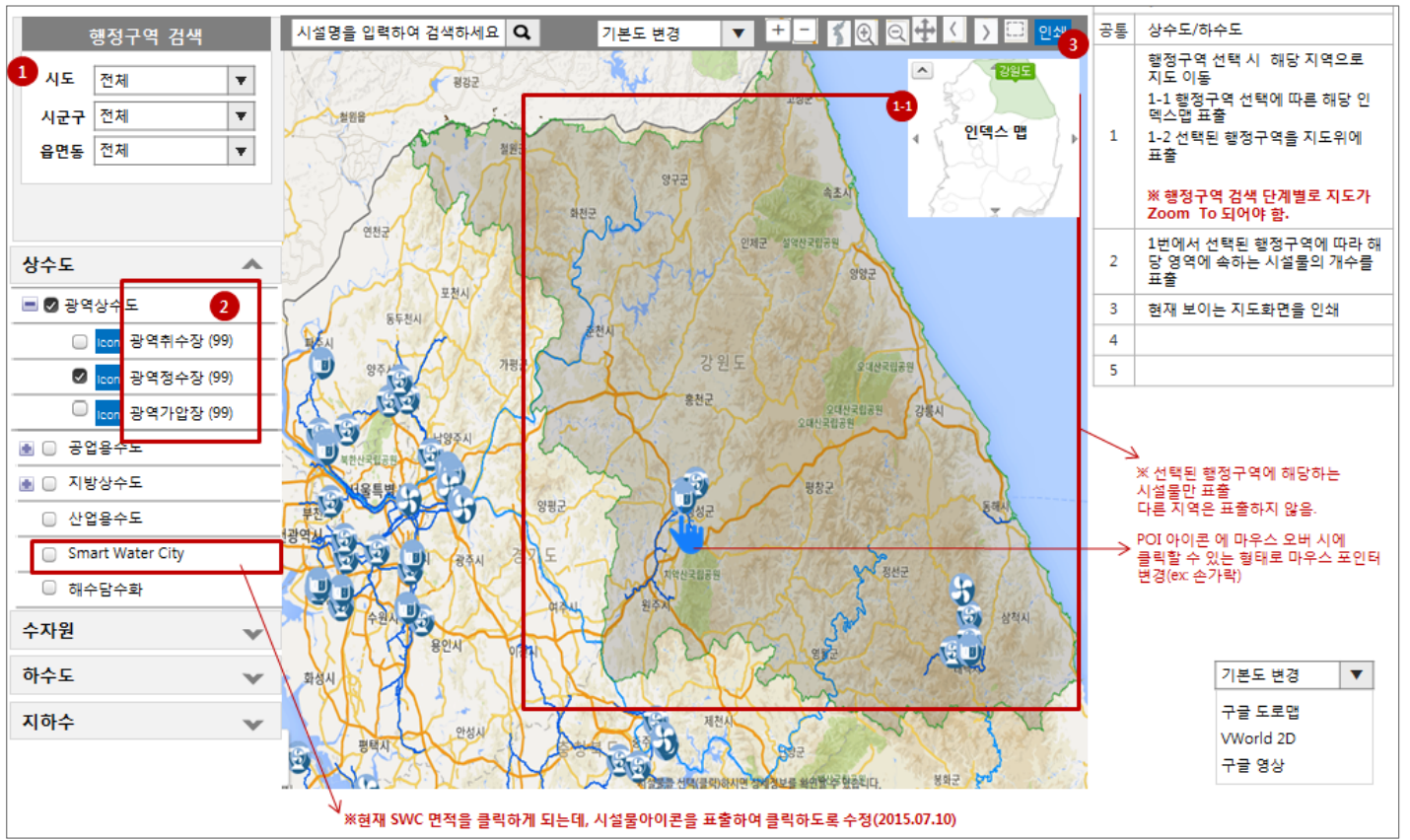

Fig. 6. User interface definition (water supply).

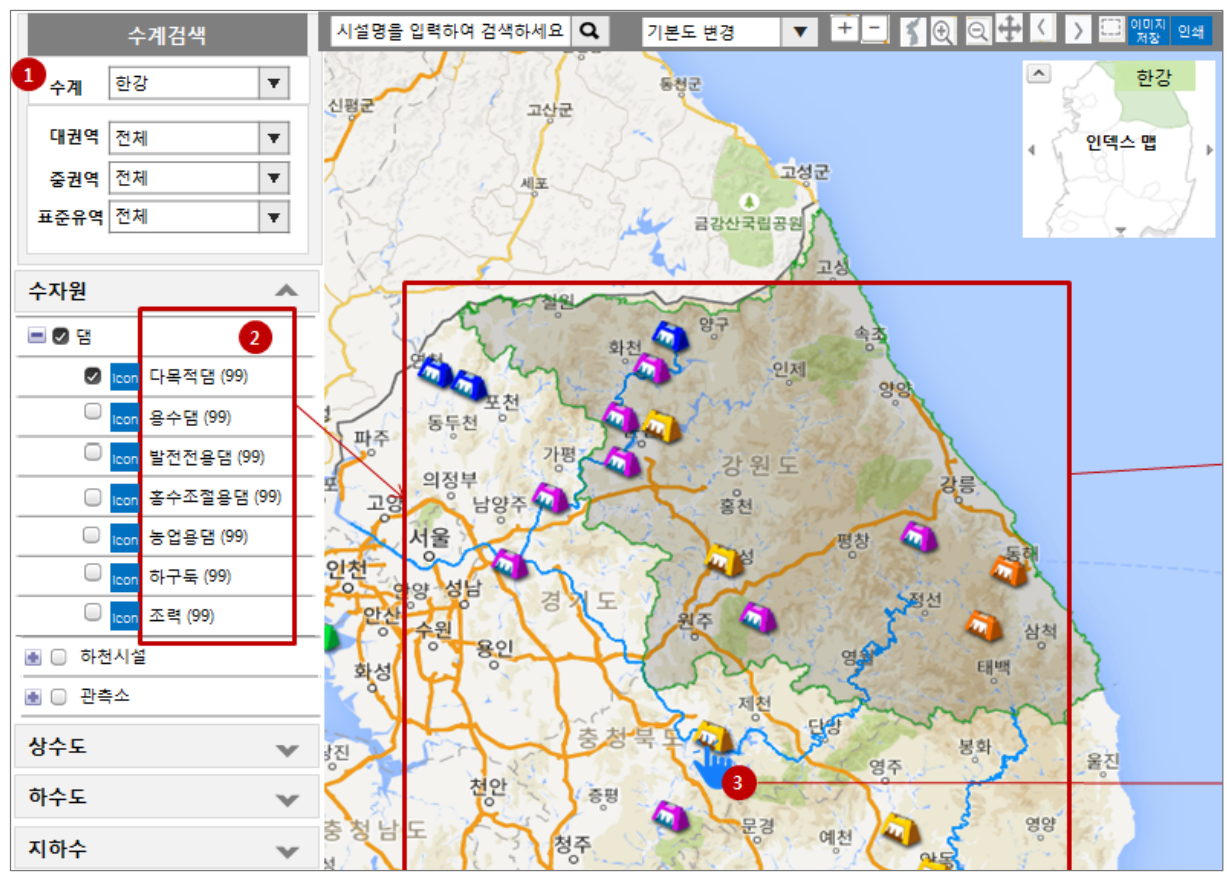

Fig. 7. User interface definition (water resources facilities). 


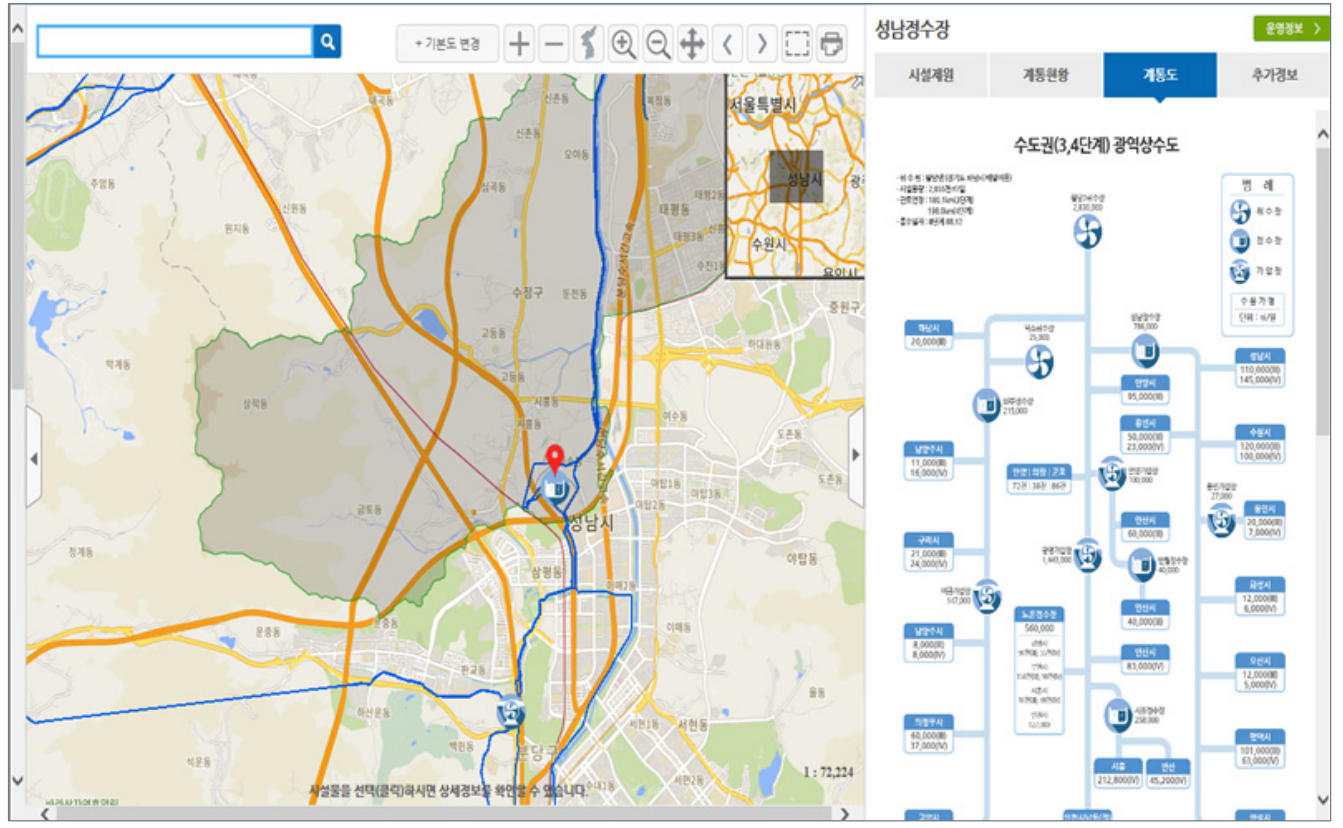

Fig. 8. User interface definition (water supply information inquiry) ${ }^{8)}$

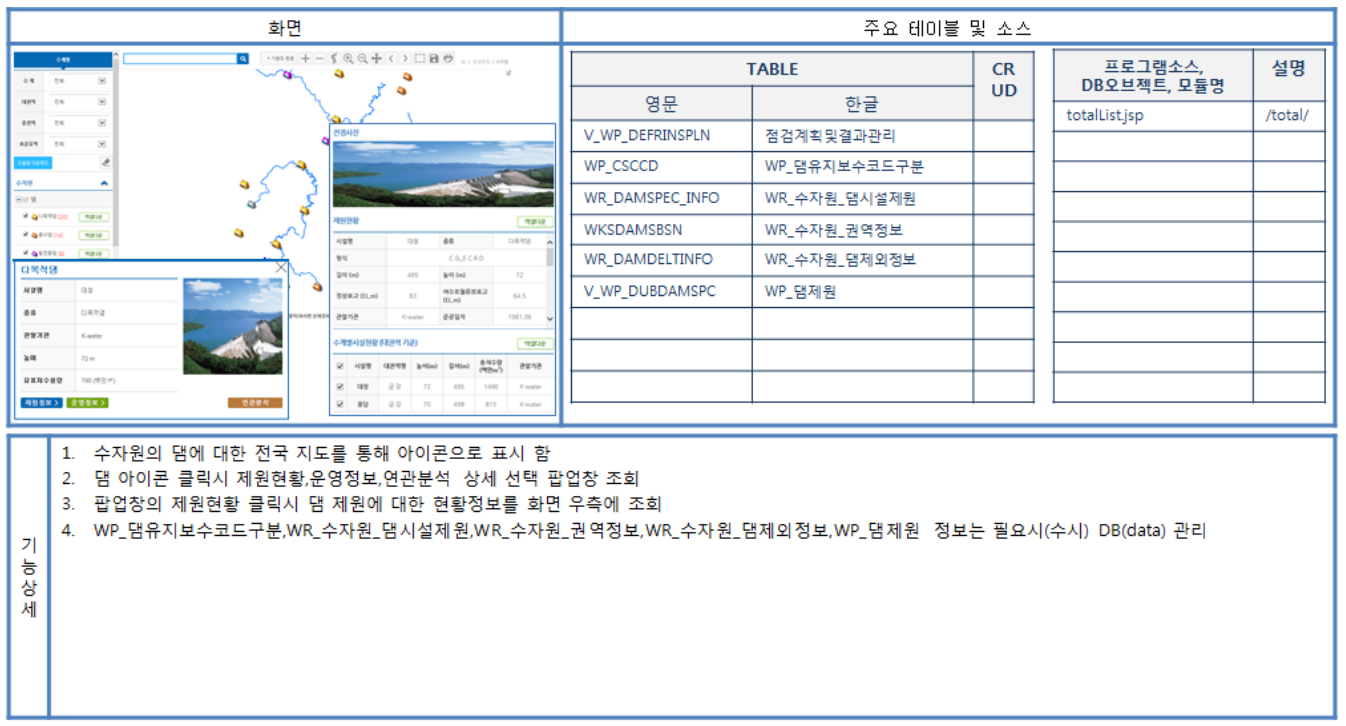

Fig. 9. Database link definition.

정구역을 지도상에 표시하고, 검색단계별로 지도가 확대되 도록 정의하였다. 선택된 행정구역에 따라 해당영역에 속하 는 시설물의 개수를 표출하고 현재 보이는 지도화면을 인 쇄 또는 이미지 파일로 저장할 수 있도록 정의하였다.

지도는 댐과 마찬가지로 시도, 시군구, 읍면동으로 확대해 들어가면 해당 지역만을 음영처리토록 하고, 해당 지도 시 설물 클릭시 해당 시설물에 대한 시설정보(운영정보)가 우 측 창에 표출되도록 정의하였다(Fig. 8). 하수도, 지하수 데 이터 표출도 동일한 UI로 정의한 바 세부사항은 생략코자 한다. 화면정의서 작성시 중요한 사항중 하나는 Fig. 9와 같 이 화면 정의뿐만 아니라 표출할 데이터의 위치를 정확히 기재하여야 한다는 것이다. 관련 데이터를 저장하고 있는 데이터베이스, 테이블, 컬럼명을 양식에 따라 기재한다. 데
이터베이스 연계 정의서는 각각의 화면마다 작성하였다.

\subsection{GIS와 실시간 데이터의 결합}

\subsubsection{GIS (Geographic Information System)의 정의와 구성}

GIS는 넓은 의미로 인간의 의사결정 능력의 지원을 위해 공간상 위치를 나타내는 도형데이터와 이와 관련된 속성데 이터를 연결하여 처리하는 정보시스템이라 할 수 있으며, 다 양한 형태의 지리정보를 효과적으로 수집, 저장, 분석, 제 공하기 위해 활용되는 하드웨어, 소프트웨어, 데이터 및 인 적자원의 통합적 시스템이다. 지리정보는 속성정보와 결합 된 공간정보를 의미한다.

이러한 지리정보가 체계적이고 구조화되어 전자적 집합체 
형태로 저장되면 이를 GIS 데이터베이스라고 한다. 지리정 보를 구성하는 공간정보, 즉 도형데이터는 벡터 데이터와 래스터 데이터로 구성된다. 이 둘 모두 GIS세계에서 현실 세계의 대상물을 표현하기 위한 것이다.

벡터 데이터는 도로, 건물, 하천과 같이 지표면에서 명확 히 구분되는 대상물을 포인트, 라인, 폴리곤 형태로 표현한 다. 이에 반해 래스터 데이터는 동일한 크기의 셀을 격자 형 태로 구성하여 지표면을 표현한다.

벡터 데이터와 래스터 데이터 모두 도형데이터를 표현하 는데 유용하지만, 일반적으로 벡터 데이터는 구분이 명확 한 경계선을 가지는 대상을 표현할 때 유용하며, 래스터 데 이터는 잘 정의된 경계가 없고 고도, 강수량, 기온과 같이 주어진 영역에서 서서히 변화하는 연속적인 도형데이터를 표현하는데 유용하다. 벡터 데이터는 데이터베이스에 저장 될 때 특정파일 형식으로 저장되는데, 이는 다양한 소프트웨 어에 따라 다른 형식으로 나타난다. 대표적인 벡터 데이터 파일형식은 shape, $\mathrm{CAD}, \mathrm{VPF}$ 등이 있다. 래스터 데이터는 $\mathrm{JPG}, \mathrm{BMP}, \mathrm{TIFF}, \mathrm{DEM}$ 등과 같은 그림파일이 대부분이다. 속성데이터는 해당 도형데이터의 특성을 정의한 것으로, 예컨대 도형데이터가 토지라고 한다면, 해당 대상물의 지 번, 면적, 소유주, 토질 등을 속성데이터라고 할 수 있다.

이러한 지리정보의 특징으로는, 앞서 밝힌 바와 같이 도 형데이터와 속성데이터의 상호연계를 통해 사용자가 원하 는 정보를 상호검색할 수 있다는 것과, 객체간의 상호인접 성, 연결성 및 포함성 등의 특성을 바탕으로 일정조건을 만 족하는 지역이나 객체를 분석, 검색할 수 있다는 것이다. 또한 일정기간동안 수집된 데이터를 수집, 저장함으로써 시계열적 공간분석도 가능하다. ${ }^{9)}$

\subsection{2. 통합시스템의 GIS 활용}

통합시스템의 가장 큰 장점은 정부부처, 물기관간 흩어져 있는 실시간 물관련 데이터를 통합하고 GIS기반의 시공간 연계 통합 정보를 제공해 준다는 것이다. 즉 물순환과정을 고려한 통합적 관점에서 지리정보와 시계열 특성을 파악할
수 있는 실시간 물관련 데이터를 사용자 관점에서 접근하 기 쉽고, 이해하기 쉽게 제공한다.

이를 위해 메뉴 구성을 수자원, 상수도, 하수도, 지하수의 네 가지 대메뉴로 나누고, 시설물 종류별로 그룹핑하여 중 메뉴를 구성한다. 수자원의 예를 들어 설명하면, 사용자는 화 면좌측 메뉴창의 해당 수계, 대권역, 중권역, 표준유역 순으 로 검색범위를 좁혀가며 원하는 수계내 시설물의 데이터를 검색할 수 있다. 또한 개략적인 시설물명을 알고 있을 경우 키워드 검색을 통해 시설물을 검색할 수도 있다. 통합시스 템의 수자원 데이터는 댐, 하천시설, 그리고 관측소 17,423 개소의 위치, 제원 데이터 및 실시간 관측, 계측 데이터로 구성된다.

다시 댐 데이터는 세부적으로 다목적댐, 용수댐, 발전용댐, 홍수조절댐, 농업용댐, 하구둑 데이터로 구분되고, 하천시 설은 양배수장과 4대강사업을 통해 건설된 다기능보 데이 터로 구분된다. 또한 수자원관측소는 수위, 우량, 기상관측 소와 수질측정망 데이터로 구분된다.

\section{4. 데이터 처리 및 추가 확보 필요성}

\subsection{1. 통합시스템 데이터 처리 프로세스}

$\mathrm{K}$-water가 자체 생산, 저장, 제공할 뿐만 아니라 정부, 외 부기관으로부터 연계하여 제공하는 수자원, 수도, 지하수 분 야의 물정보는 국내생산 물정보의 약 $63 \%$ 를 차지한다. 통 합시스템은 K-water가 보유하고 있는 수자원, 수도, 지하수 의 위치, 제원정보 및 실시간으로 관측, 계측되는 데이터를 보여주는데 그 프로세스는 다음과 같다. 먼저 사용자가 통합 시스템의 웹페이지에 접속하여 원하는 정보를 호출하면, WAS (Web Application Server)가 이를 받아 위치정보 연산은 GIS 서버가 수행토록 명령을 내리고, 제원 및 실시간 데이터는 내부 데이터베이스(INFOS, TECH, TRAN DB)로부터 관련 정보를 받아 WAS가 자체처리를 수행한다. 이렇게 처리된 위 치, 제원 및 실시간 데이터는 WAS를 거쳐 외부망의 WEBTOB 서버로 보내져 사용자 화면에 표출되게 된다. Fig. 10은 통 합시스템의 데이터 처리 프로세스를 보여준다.

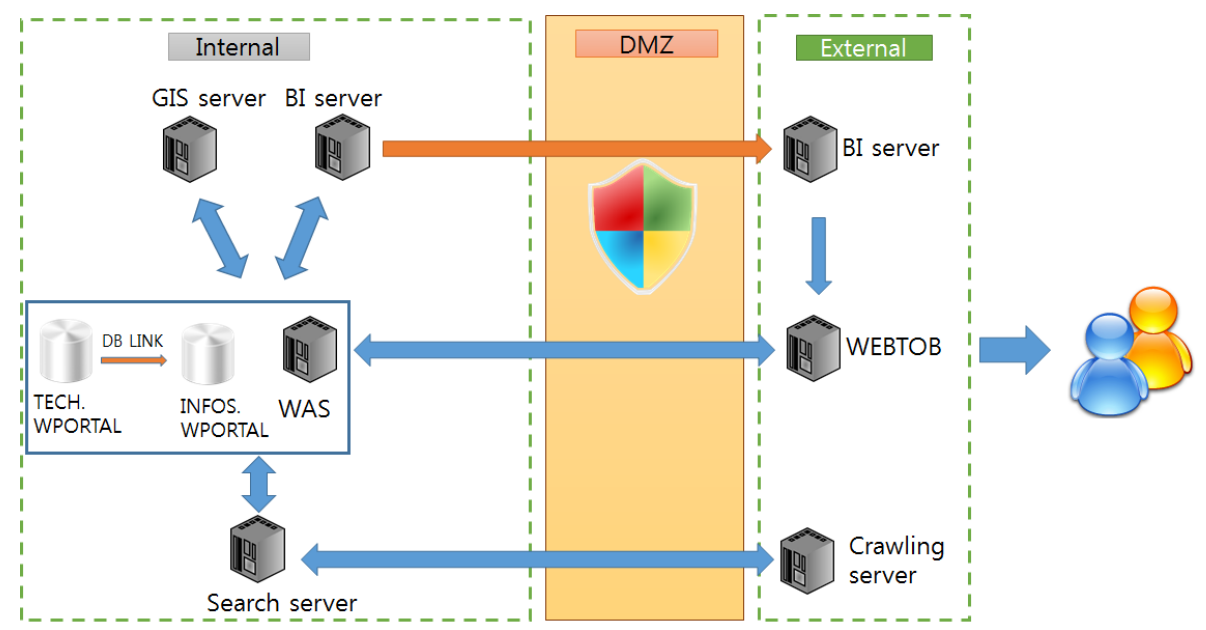

Fig. 10. Data processing procedure of integrated system. 


\subsection{2. 물정보의 추가 확보 필요성}

향후 흩어져있는 국내 물정보를 추가적으로 확보하여 물 정보 통합, 활용 기반을 강화해 나감으로써 다음과 같이 효 율적인 수자원관리가 가능해진다. ${ }^{10)}$ 첫 번째는 각각의 물 기관의 임무에 부합토록 한정된 자료만 활용된 현재 가뭄 평가 방식(기상학적(기상청), 농업적(농어촌공사), 수문학적 (국토부) 가뭄평가)으로는 국내 물관리 여건 전반이 반영된 정확한 가뭄파악과 전망, 이를 통한 선제적 대응에 한계가 있다. 수자원시설의 수원상황과 공급지역에 대해 생활용수, 공업용수, 농업용수기준으로 공급가능여부, 전망을 통해 실질적 가뭄상황 모니터링 및 정보제공이 필요하다.

두 번째는 수계 전반의 홍수상황을 고려한 효율적 연계 운영으로 홍수피해 저감이 가능하다는 것이다. 하천유량 및 다양한 수자원시설의 저수량, 저수율, 방류량 자료를 통해 수계 전반의 홍수상황을 파악함으로써 홍수에 대한 효율적 대응이 무엇보다 절실하다. 세 번째는 상수도 실시간 수질 데이터 확보, 제공을 통해 내가 사는 지역의 수돗물이 얼마 나 깨끗하고 안전한지 제공이 가능하다는 점이다.

이를 통해 직접 음용률 향상 및 수돗물 신뢰도 제고가 가능하다는 것은 파주 $\mathrm{SWC}$ 사업 ${ }^{11)}$ 을 통해 이미 증명된 바 있다(수돗물 신뢰 제고 및 소비자 중심의 새로운 물 관리 모델 정립을 위한 파주시 Smart Water City 시범사업을 추 진('14년 '16년), 주요성과는 수질개선 및 유수율 제고, 수 돗물 직접 음용률 향상, 최소 $1.0 \% \rightarrow$ 최대 $41.5 \%$ ).

본 연구는 K-water가 자체 생산, 저장, 제공할 뿐만 아니 라 정부, 외부기관으로부터 연계하여 제공하는 수자원, 수 도, 지하수 분야의 물정보 활용을 전제로 하고 있다. 그 외 흩어져있는 국내 물정보를 추가적으로 확보하여 제공하기 위해서는 첫째, 정부 3.0 에 근거하여 국가, 공공기관이 가지 고 있는 데이터를 요청하고 openAPI 방식 등을 통해 주기 적으로 전송받아 확보하는 방안이 있다. 두 번째로는 해당 기관의 내부망에 전용서버를 설치하고 전용통신망을 통해 정보를 직접 취득하는 방법이다. 다만 이 경우 openAPI방 식 보다는 보다 면밀한 협의가 필요하며 설치, 유지 및 관 리를 위한 비용이 수반된다. 무엇보다 물순환 전반에 걸친 원천 데이터 취득, 관리 및 정보화를 위해서는 정부주도의 노력이 절실히 요구된다. 수문, 수질, 생태 등의 데이터 관 측 및 취득을 강화하기 위해서는 국토부, 환경부를 주축으 로 범정부적인 노력이 필요한데 이를 위해 정부가 추진하 는 물관리일원화 정책은 매우 시기적절하다고 판단된다.

\section{5. 물정보 통합관리시스템의 구현}

본 연구에서는 물정보 통합관리시스템 개발을 위한 목표 수준을 설정하고 시스템을 구현하기 위한 개발 프로세스, 화 면정의, 데이터 통합 및 추가확보 등에 대하여 다루었다. 본 연구에서 제시한 목표수준에 부합하는 시스템환경 구현을 위 해서는 첫째, 국내 물정보를 관리, 제공하는 데이터베이스 허브의 확보가 전제되어야 한다. 따라서 K-water가 기확보 하고 있는 물정보를 우선 활용하여 시스템을 개발하되, 향
후 물정보 확대를 염두에 두고 시스템 확장이 용이하게 할 필요가 있다. 두 번째로 실제 시스템 개발에 있어, 하드웨어 측면에서는 $\mathrm{K}$-water내부의 각각의 $\mathrm{DB}$ 들로부터 필요한 물 정보를 받아 저장, 제공하는 통합DB가 구축되어야 한다.

또한 통합DB로부터 필요한 데이터를 받아 사용자가 원하 는 결과를 도출하기 위한 연산작업을 수행하는 Web Application Server와 조회결과를 사용자에게 표출하는 웹서버도 구축되어야 한다. 소프트웨어 측면에서는 시스템 개발을 위 한 웹개발자, GIS전문가, 퍼블리셔, $\mathrm{DBA}$ (데이터베이스관 리자) 등의 IT전문인력을 갖추어야 한다. 따라서 본 연구와 연계하여 실제 시스템을 개발, 서비스하기 위해서는 국내 물 정보의 상당부분을 생산, 관리 또는 연계, 보유하고 있는 $\mathrm{K}$-water의 참여가 필요하다(본 연구에 이어 $\mathrm{K}$-water는 통 합시스템 개발, 구축을 완료하고, ' 16 년 1월부터 K-water의 물정보포털, MyWater에 탑재하여 웹서비스 중).

\section{4. 결 론}

통합물관리의 패러다임이 ICT 기술의 발전으로 인해 정 부 부처, 지자체, 물기관간 조직, 업무의 물리적 통합에서 물정보를 통합하는 방향으로 변화의 흐름이 감지되고 있 다. 이에 K-water가 자체 생산하는 물정보와 정부, 지자체, 물기관이 보유하고 있는 물정보를 한데 모아 표출하는 통 합시스템 개발 연구를 하기에 이르렀다. 통합시스템은 흩 어져 있는 국내 물 관련 시설 생산정보의 약 $63 \%$ 를 한데 모 아 GIS와 결합하여 시각화를 극대화 시키는 것이다. 그 효 과는 다음과 같이 요약할 수 있다.

첫째, 기 확보된 정부부처, 물기관의 물정보를 활용하여 전국의 수자원, 수도, 지하수 시설물의 위치와, 실시간 운영 정보를 한 눈에 볼 수 있도록 함으로써 정보기반의 통합물 관리 모델을 제시한다.

둘째, 홍수, 가뭄 등 풍수해 재난대책 수립 및 대응이 가 능해 질 것이다. 모든 공공기관의 수문 관측 정보와 생활, 농 업, 공업용수 수용가 정보를 통합할 경우 이를 홍수, 가뭄 분 석에 활용하여 예경보 정확도를 향상시킬 수 있고, 사후 복구 및 지원방향에 대한 의사결정에도 활용할 수 있을 것이다.

셋째, 하천 수질사고 대응도 가능해 질 것이다. 댐 방류 량, 각 수위국 수위 정보, 각 지자체 하천 취수장 및 정수 처리시설 운영현황, 용수공급구역 정보 및 화학단지, 공업 단지 등 점오염원 배출지역 정보를 통합하면 수원에 오염 원 유입시 신속한 대응 및 의사결정이 가능해질 것이다.

\section{Acknowledgement}

본 연구는 국토교통부 플랜트연구개발사업의 연구비지원 (과제번호 17IFIP-B088091-04)에 의해 수행되었습니다. 


\section{References}

1. K-water, "Comprehensive water informatization plan for integrated water management,"(2016. 7.).

2. K-water, Joongbu university industry-academia collaboration foundation, "Master plan for K-water's big data based water information integration management system,"(2015. 4.).

3. Ministry of construction and transportation, "Comprehensive water management plan,"(1996.).

4. National water supply information system, https://www.water now.go.kr(2016.).

5. Water information system, http://water.nier.go.kr/main/main Content.do(2016.).

6. CUAHSI, https://www.cuahsi.org/(2016.).

7. K-water, "Terms of reference for development services on the water information portal,"(2015.).

8. Actually implemented user interface, http://www.water.or.kr/ $\mathrm{com} / \mathrm{kwip} /$ totalaction.do?mparam $1=$ 상수도\&mparam2=광역 상수도\&mparam $3=$ 광역취수장 \&seq=7\&p_group_seq= 2\&menu_mode=0\#none(2017.).

9. K-water, "Operation manual for GIS,"(2012. 7.).

10. K-water, "Project plan for K-water's water information management,"(2014. 10.).

11. K-water, "Final outcome for Paju SWC pilot project,"(2016. 11.). 